\title{
"Consilium". Teorie e pratiche del consigliare nella cultura medievale, a cura di Carla Casagrande, Chiara Crisciani, Silvana Vecchio
}

\section{G. Matteo Roccati}

\section{(2) OpenEdition}

\section{Journals}

Édition électronique

URL : http://journals.openedition.org/studifrancesi/29912

DOI : $10.4000 /$ studifrancesi.29912

ISSN : 2421-5856

Éditeur

Rosenberg \& Sellier

\section{Édition imprimée}

Date de publication : 1 avril 2006

Pagination : 125-126

ISSN : 0039-2944

\section{Référence électronique}

G. Matteo Roccati, «"Consilium". Teorie e pratiche del consigliare nella cultura medievale, a cura di Carla Casagrande, Chiara Crisciani, Silvana Vecchio », Studi Francesi [En ligne], 148 (XLX | I) | 2006, mis en ligne le 30 novembre 2015, consulté le 19 avril 2021. URL : http://journals.openedition.org/ studifrancesi/29912 ; DOI : https://doi.org/10.4000/studifrancesi.29912

Ce document a été généré automatiquement le 19 avril 2021.

\section{cc) $(9)$}

Studi Francesi è distribuita con Licenza Creative Commons Attribuzione - Non commerciale - Non opere derivate 4.0 Internazionale. 


\title{
"Consilium". Teorie e pratiche del consigliare nella cultura medievale, a cura di Carla Casagrande, Chiara Crisciani, Silvana Vecchio
}

\author{
G. Matteo Roccati
}

\section{RÉFÉRENCE}

"Consilium". Teorie e pratiche del consigliare nella cultura medievale, a cura di CARLA CASAGRANDE, CHIARA CRISCIANI, SILVANA VECCHIO, Firenze, Sismel, Edizioni del Galluzzo (« Micrologus’ Library », 10), 2004 ; pp. X-346.

1 L'ouvrage, fruit des communications présentées lors d'un colloque tenu à Pavie en décembre 2000, comprend seize contributions. En dehors de plusieurs études ponctuelles, on y trouvera quelques articles de synthèse sur les domaines juridique, théologique, médical et des arts magiques: MARIO ASCHERI, Il consilium dei giuristi medievali, pp. 243-258; SILVIA NAGEL, Il consilium nella letteratura ebraica medievale: la tradizione dei responsa rabbinici, pp. 299-325; MARIA LUISA PICASCIA, La concezione teologica di donum consilii. Patristica latina e cultura monastica del XII secolo, pp.15-32; SILVANA VECCHIO, Precetti e consigli nella teologia del XIII secolo, pp.33-56; GABRIELLA ZARRI, Dal consilium spirituale alla discretio spirituum. Teorie e pratica della direzione spirituale tra $i$ secoli XIII e XV, pp. 77-107 (sur la tradition de la direction spirituelle et notamment sur les traités de Jean Gerson); CHIARA CRISCIANI, Consilia, responsi, consulti. I pareri del medico tra insegnamento e professione, pp. 259-279; VITTORIA PERRONE COMPAGNI, Precetti della magia, consigli sulla magia, pp. 281-298.

2 La dimension plus proprement politique est abordée par MARTA CRISTIANI, Ego sapientia, habito in consilio. Proverbia VIII, 12-16 nella teologia politica carolingia, pp.125-138; ENRICO ARTIFONI, Prudenza del consigliare. L'educazione del cittadino nel Liber consolationis et 
consilii d'Albertano da Brescia (1246), pp. 195-216. STEVEN J. WILLIAMS, Giving Advice and Taking It: The Reception by Rulers of the Pseudo-Aristotelian Secretum Secretorum as a Speculum Principis, pp. 139-180, étudie la réception du Secretum chez les gouvernants, en comparant cette œuvre au De regimine principum, et dresse une liste de témoignages concernant les princes de la chrétienté du XIII ${ }^{\mathrm{e}}$ au XV $\mathrm{XV}^{\mathrm{e}} \mathrm{s}$. qui ont possédé ou lu ces deux ouvrages (en latin ou en traduction vernaculaire).

3 Quelques études se réfèrent plus particulièrement à des auteurs appartenant à l'aire française. DORIS RUHE, Hiérarchies et stratégies. Le conseil en famille, pp. 109-123, donne un aperçu du devoir de conseil dans le droit féodal d'après la Chanson de Roland et se penche ensuite sur quelques manuels d'éducation - notamment le Chastoiement d'un pere a son fils et le Mesnagier de Paris. Deux contributions traitent des conseils fiscaux adressés aux rois de France et d'Angleterre au XIV ${ }^{\mathrm{e}}$ siècle: CLAUDIO FIOCCHI, Il principe e il filosofo. Consilia fiscali alla corte di Carlo V: Nicolas Oresme e Evrart de Tremaugon, pp. 217-227 ; STEFANO SIMONETTA, Il principe e il filosofo. II : Consulenti fiscali al servizio di Sua Maestà, pp. 229-241.

Le volume est complété par l'index des noms de personnes et par celui des manuscrits. 